\title{
Paper wasp nest-mediated biosynthesis of silver nanoparticles for antimicrobial, catalytic, anticoagulant, and thrombolytic applications
}

\author{
Agbaje Lateef ${ }^{1,2} \cdot$ Monsurat A. Akande $^{1} \cdot$ Sunday A. Ojo $^{1} \cdot$ Bolaji I. Folarin $^{1} \cdot$ \\ Evariste B. Gueguim-Kana ${ }^{3} \cdot$ Lorika S. Beukes $^{4}$
}

Received: 23 February 2016/ Accepted: 10 June 2016/Published online: 22 June 2016

(c) The Author(s) 2016. This article is published with open access at Springerlink.com

\begin{abstract}
Biosynthesis of silver nanoparticles (AgNPs) using nest extract of paper wasp (Polistes $\mathrm{sp}$ ) was investigated in this work. The AgNPs were characterized by UVVis spectroscopy, Fourier transform infrared spectroscopy (FTIR), and transmission electron microscopy (TEM), and evaluated for antibacterial, antifungal, dye degradation, blood anticoagulation, and blood clot dissolution (thrombolytic) activities. The crystalline polydispersed AgNPs with size range of $12.5-95.55 \mathrm{~nm}$ absorbed maximally at $428 \mathrm{~nm}$ and showed anisotropic structures of sphere, triangle, hexagon, rod, and rhombus. The FTIR data showed prominent peaks at 3426 and $1641 \mathrm{~cm}^{-1}$, which indicate the involvement of phenolics compounds and proteins in the synthesis of AgNPs. The prominence of Ag in the EDX spectra showed that indeed, AgNPs were formed. The AgNPs showed potent antibacterial activities (12-35 mm) against three multi-drug strains of Pseudomonas aeruginosa and Klebsiella granulomatis. While the growth of Aspergillus flavus and Aspergillus niger was completely
\end{abstract}

Agbaje Lateef

agbaje72@yahoo.com; alateef@lautech.edu.ng

1 Laboratory of Industrial Microbiology and

Nanobiotechnology, Department of Pure and Applied

Biology, Ladoke Akintola University of Technology, PMB

4000, Ogbomoso, Nigeria

2 Nanotechnology Research Group (NANO+), Ladoke Akintola University of Technology, PMB 4000, Ogbomoso, Nigeria

3 Department of Microbiology, School of Life Sciences, University of KwaZulu-Natal, Private Bag X01, Scottsville, PieterMaritzburg 3209, South Africa

4 Microscopy and Microanalysis Unit, School of Life Sciences, University of KwaZulu-Natal, Private Bag X01, Scottsville, PieterMaritzburg 3209, South Africa suppressed, the AgNPs produced growth inhibition of $75.61 \%$ against Aspergillus fumigatus at $100 \mu \mathrm{g} / \mathrm{ml}$. Furthermore, the AgNPs degraded malachite green to the tune of 93.1\%. The AgNPs also prevented coagulation of blood, while it completely dissolved preformed blood clots within 5 min showing the potent anticoagulation and thrombolytic activities. This study, which is the first of its kind to use nest extract of paper wasp for the synthesis of nanoparticles, has shown that the biosynthesized AgNPs could be deployed for biomedical and catalytic applications.

Keywords Wasp · Biosynthesis - Silver nanoparticles · Antimicrobial activity $\cdot$ Malachite green · Thrombolysis . TEM

\section{Introduction}

The art of synthesis and the applications of nanoparticles have continued to expand due to the abundance of biological materials that are rich in bioreductant molecules for the eco-friendly synthesis of nanoparticles. The avoidance of use of hazardous procedures has also widen the scope of biomedical applications, with appreciable level of biocompatibility and lesser toxicity compared with those synthesized using chemical route. To this extent, several biomaterials from plants, bacteria, fungi, algae, and among others have been used to produce nanoparticles (Kumar et al. 2012; Roopan et al. 2013; Velayutham et al. 2013; Das et al. 2014; Kumar et al. 2014; Metuku et al. 2014; Lateef et al. 2015a, b, c, 2016a, b; Lateef and Adeeyo 2015; Waghmare et al. 2015; Yugandhar et al. 2015). To expand the frontiers of applications of biomolecules for the green synthesis of nanoparticles, some recent studies have focused on the use of metabolites from arthropods $\mathrm{Xu}$ 
et al. 2013; Aramwit et al. 2014; Lateef et al. 2015d). Among several metallic nanoparticles, silver nanoparticles (AgNPs) have been the most studied due to the versatility of its applications for diverse biological, biomedical, catalytic, electrical, and electrochemical purposes. These have made AgNPs to be of high relevance in environmental, catalytic, healthcare, food, agriculture, biomedical, and textile applications (Keat et al. 2015).

Paper wasps of the genus Polistes have been the most studied among the eusocial wasps (Hymenoptera, Vespidae, Polistinae), of which about 200 species of cosmopolitan occurrence had been described (West-Eberhard 2006; Sinzato et al. 2011; Nguyen and Kojima 2014). Polistes make colonies usually consisting of about 100 individuals that live in non-enveloped nests, which are made on twigs, leaves, dense shrubs and grass, hollow trees and elevated natural cavities, and manmade structures (Wenzel 1996; Clapperton and Lo 2000). The nests, which are paper-like in form, are derived from the foraging activities of wasps on plant materials (Evans and West-Eberhard 1970), and served as compartments to oviposit eggs by young females. In addition to richness in cellulose, the nests of Polistes have reportedly being rich in proteins with more than 20 amino acids detected from field and laboratory nests, of which glycine, serine, alanine, valine, and proline were the most prevalent amino acids (Singer et al. 1992; Kudô et al. 2000a, b). Though arthropods are abundantly rich in the synthesis of novel biomaterials, such as silk, cobwebs, and nests, the use of metabolites from arthropods for the green synthesis of nanoparticles seems to be at infancy with a few literature reports (Xu et al. 2013; Aramwit et al. 2014; Lateef et al. 2015d). Therefore, there is need to explore arthropods for their nanobiotechnological applications.

In our previous study, we have shown that a similar biomaterial, spider cobweb could be used for biosynthesis of AgNPs with potent antimicrobial activities (Lateef et al. 2015d). Therefore, this work was conceptualized to evaluate the potential of nest of paper wasp for the green and eco-friendly synthesis of AgNPs, thereby finding a biotechnological utilization of the biomaterial. The study further examined the antibacterial, antifungal, malachite degradation, blood anticoagulation, and thrombolytic (lysis of blood clots) activities of the biosynthesized AgNPs. To the best of our knowledge, this is the first report of the use of paper wasp's nest for the biosynthesis of AgNPs.

\section{Materials and methods}

\section{Preparation of paper wasp nest extract}

Nests of paper wasp were obtained from a residential building in Ogbomoso, Southwest Nigeria. The nests were taken to the laboratory and washed thoroughly using distilled water to remove dust and other extraneous materials. The washed nest was allowed to air-dry at room temperature $\left(30 \pm 2{ }^{\circ} \mathrm{C}\right)$ and kept in air-tight container until further use. The modified method of Tszydel et al. (2009) as previously reported (Lateef et al. 2015d) was used to hydrolyze the nests. About $0.1 \mathrm{~g}$ of the nest was weighed and hydrolyzed with $10 \mathrm{ml}$ of $0.1-\mathrm{M} \mathrm{NaOH}$ at $90{ }^{\circ} \mathrm{C}$ for $1 \mathrm{~h}$. The hydrolyzed nest was allowed to cool, centrifuged at $4000 \mathrm{rpm}$ for $30 \mathrm{~min}$, and used without further purification.

\section{Biosynthesis and characterization of AgNPs}

Biosynthesis of AgNPs was carried out as earlier reported (Lateef et al. 2015d) by reacting $1 \mathrm{ml}$ of nest extract with $40 \mathrm{ml}$ of $1-\mathrm{mM}$ silver nitrate $\left(\mathrm{AgNO}_{3}\right)$ solution for the reduction of silver ion. The reaction was carried out in static condition at room temperature $\left(30 \pm 2{ }^{\circ} \mathrm{C}\right)$ for $30 \mathrm{~min}$. AgNPs biosynthesis was monitored through visual observation of the change of color and measurement of the absorbance spectrum of the reaction mixture using $\mathrm{UV}-\mathrm{V}$ is spectrophotometer (Cecil, USA).

Fourier transform infrared (FTIR) spectroscopy analysis was carried out using IRAffinity-1S spectrometer (Shimadzu, UK) on the powder sample of AgNPs. The AgNPs solution was centrifuged at $10,000 \mathrm{rpm}$ for $20 \mathrm{~min}$. The solid residue obtained was then dried at room temperature, and the powder obtained was used for FTIR measurement using $\mathrm{KBr}$ pellets.

The transmission electron microscopy (TEM) micrograph was obtained as follows. A drop of nanoparticles in suspension was placed on a 200-mesh hexagonal copper grid $(3.05 \mathrm{~mm})$ (Agar Scientific, Essex, UK) coated with $0.3 \%$ formvar dissolved in chloroform. The particles were allowed to settle for 3-5 min on the grid, the excess liquid flicked off with a wick of filter paper, and the grids were then air dried before TEM viewing. Micrograph was obtained using a JEM-1400 (JEOL, USA) operating at $200 \mathrm{kV}$.

\section{Antimicrobial activities of synthesized AgNPs}

The antimicrobial investigations involved the use of Klebsiella granulomatis and Pseudomonas aeruginosa, which were obtained from LAUTECH Teaching Hospital, Ogbomoso, and fungal strains of Aspergillus niger, Aspergillus flavus, and Aspergillus fumigatus. For antibacterial evaluation, each bacterium was grown overnight in peptone water, and $18 \mathrm{~h}$-culture $\left(\sim 1 \times 10^{6} \mathrm{cfu} /\right.$ ml) was used to seed the plates of Mueller-Hinton Agar (Lab M Ltd.). Thereafter, the plates were then bored using cork borer $(7 \mathrm{~mm})$ to create wells, to which $100 \mu \mathrm{l}$ of 
graded concentrations $(10-100 \mu \mathrm{g} / \mathrm{ml})$ of AgNPs prepared by dispersion in sterile distilled water were added. The plates were incubated at $37{ }^{\circ} \mathrm{C}$ for $24 \mathrm{~h}$, for the examination of zones of inhibition, which were measured. The antifungal activities of the biosynthesized AgNPs were evaluated using the methods of Khatami et al. (2015) by incorporating graded concentrations of AgNPs into potato dextrose agar plates, which were then inoculated with agar plug of $6 \mathrm{~mm}$ of 48-h old cultures of Aspergillus niger, Aspergillus flavus, and Aspergillus fumigatus. In the control experiments, fungal plugs were inoculated on PDA plates without the incorporation of AgNPs. All the plates were incubated at $28 \pm 2{ }^{\circ} \mathrm{C}$ for $72 \mathrm{~h}$. The diameters of fungal growths in all the plates were measured and used to determine the percentage growth inhibitions as follows: $\frac{D_{\text {control }}-D_{\text {test }}}{D_{\text {coutrol }}} \times 100 \%$ where $D$ is the diameter of fungal growth on the PDA plates.

\section{Dye-degradation activities of AgNPs}

This was investigated through the decolorization of malachite green, by reacting $1 \mathrm{ml}$ of the biosynthesized AgNPs at concentration of 20 and $40 \mu \mathrm{g} / \mathrm{ml}$ with $9 \mathrm{ml}$ of $40 \mathrm{ppm}$ of malachite green, while the control experiment consisted of $10 \mathrm{ml}$ of the dye only. All the reaction vessels were subjected to agitation on a rotary shaker at $100 \mathrm{rpm}$ for up to $24 \mathrm{~h}$ under ambient temperature of $30 \pm 2{ }^{\circ} \mathrm{C}$. The absorbance values of the reaction mixtures were determined using UV-Vis spectrophotometer at wavelength of 619 to calculate the percentage dye degradation as follows: Percentage dye degradation $=\frac{A_{\text {control }}-A_{\text {test }}}{A_{\text {control }}} \times 100 \%$ where $A$ is the absorbance at $619 \mathrm{~nm}$.

\section{Anticoagulant and thrombolytic activities of biosynthesized AgNPs}

The anticoagulant activity of the AgNPs was investigated by mixing $0.5 \mathrm{ml}$ of $150 \mu \mathrm{g} / \mathrm{ml}$ of nanoparticles with $5 \mathrm{ml}$ of freshly collected human blood from a healthy volunteer and then held at ambient condition $\left(30 \pm 2{ }^{\circ} \mathrm{C}\right)$ to observe visually for the coagulation of blood. In the control experiments, blood samples collected in EDTA bottle, and in ordinary clean bottle served as positive and negative control, respectively. The method of Harish et al. (2015) was used for the thrombolytic assay. Blood clot formed in vitro was spread on clean, grease-free glass slides, and then treated with $0.2 \mathrm{ml}$ of AgNPs. This was monitored for the dissolution of the clot. The control experiments consisted of untreated blood clots, and that treated with $\mathrm{AgNO}_{3}$ solution and the nest-extract only. After visual observation, both anticoagulation and thrombolytic activities of the biosynthesized AgNPs were assessed through optical microscopy by capturing images of blood samples smeared on slides on an Olympus microscope.

\section{Results and discussion}

\section{Biosynthesis and characterization of AgNPs}

The nest extract with $\mathrm{pH}$ of 10.5 catalyzed the bioreduction of silver ion to produce metallic AgNPs with $\mathrm{pH}$ of 8.3 within $5 \mathrm{~min}$. The AgNPs was brownish in color which stabilized after $10 \mathrm{~min}$ of reaction (Fig. 1). Several authors have reported color formation ranging from light yellow, yellow brown to dark brown for colloidal AgNPs (Das et al. 2014; Emeka et al. 2014; Lateef et al. 2015a, b, c, d; Netala et al. 2015) due to variations in the composition of bioreductant molecules which influence the surface plasmon resonance. Reports have indicated that nests of paper wasps are rich in proteins with abundant presence of amino acids (Singer et al. 1992; Kudô et al. 2000a, b) which could readily serve as bioreductant molecules for the green synthesis of AgNPs. In an earlier work, we established that proteinous molecules in the spider cobwebs were responsible for the green synthesis of AgNPs (Lateef et al. 2015d). Therefore, this work has further shown that metabolites of paper wasps can find application in the synthesis of nanoparticles.

The colloidal AgNPs absorbed maximally at $428 \mathrm{~nm}$ (Fig. 2) with a broad peak that may depict polydispersed nanoparticles. The observed maximum absorbance falls within the range previously reported (Emeka et al. 2014; Anandalakshmi et al. 2015; Kathiraven et al. 2015; Lateef et al. 2015b, d). In the FTIR studies, prominent peaks were obtained at 3426 and $1641 \mathrm{~cm}^{-1}$, in addition to minor peaks at 3811,2367, 2089, 1365, 1236, 486, and $444 \mathrm{~cm}^{-1}$ (Fig. 3). The major peaks at 3426 and $1641 \mathrm{~cm}^{-1}$ correspond to $\mathrm{N}-\mathrm{H}$ of amines or $\mathrm{O}-\mathrm{H}$ stretch of carboxylic acid, $\mathrm{C}=\mathrm{C}$ stretch of alkenes or $\mathrm{C}=\mathrm{O}$ stretch of amides, respectively (Emeka et al. 2014; Shankar et al. 2014) indicating the involvement of phenolics and proteins in the biosynthesis of AgNPs. While the presence of amino acids in the nests of paper wasps has been fully established (Singer et al. 1992; Kudô et al. 2000a, b), the occurrence of phenolics is unexpected, since the nests are largely produced from plant-based materials. It can, therefore, be concluded that proteins and phenolics present in the nest extract served as both capping and stabilization molecules in the synthesis of AgNPs.

The TEM result showed the formation of anisotropic structures with size range of 12.5-95.55 nm (Fig. 4a), which are well dispersed without any form of aggregation. The size range fully supports the polydispersed nature of the particles as shown in the broad band peak of the UV- 
Fig. 1 The biosynthesis of AgNPs using paper wasp nest extract

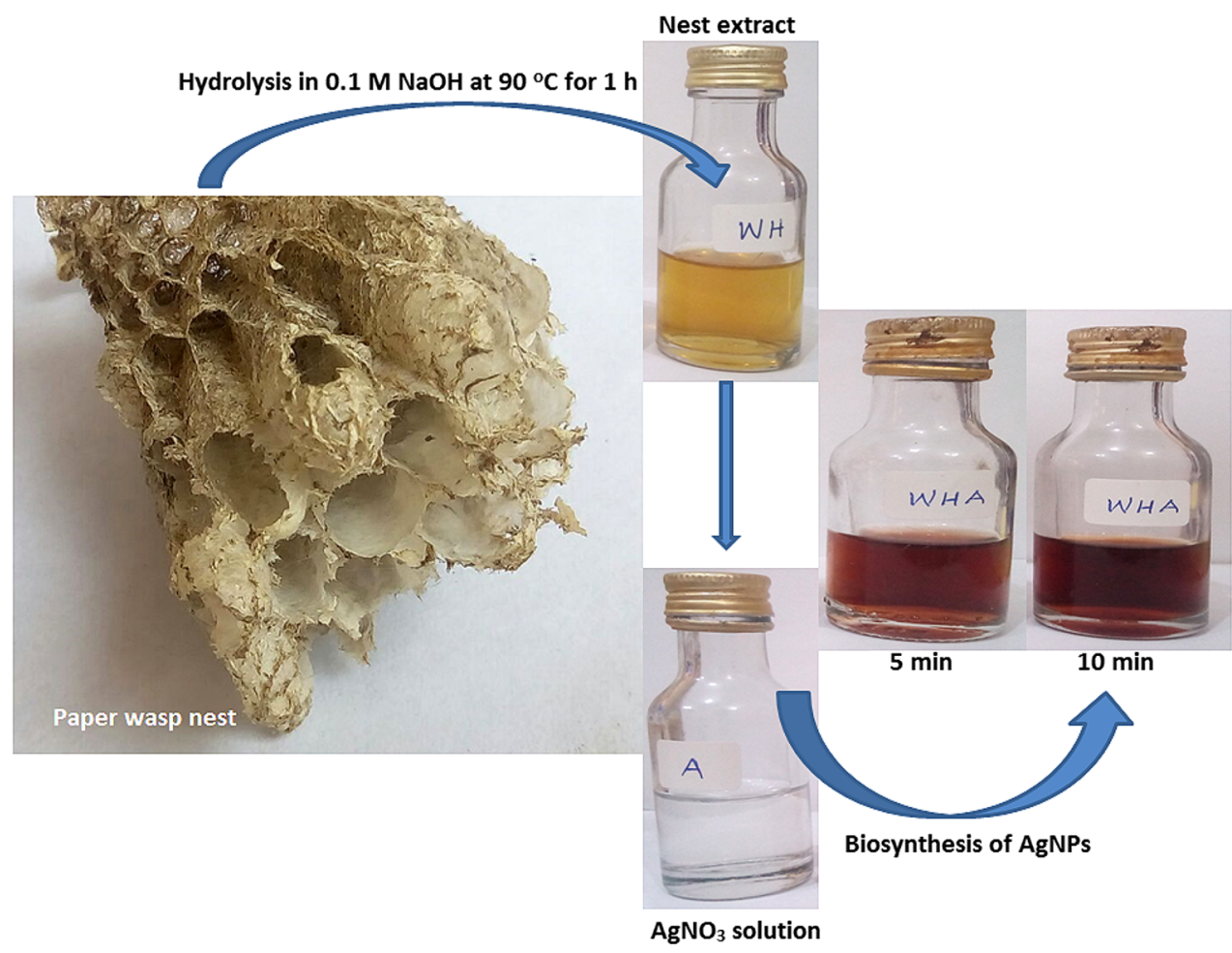

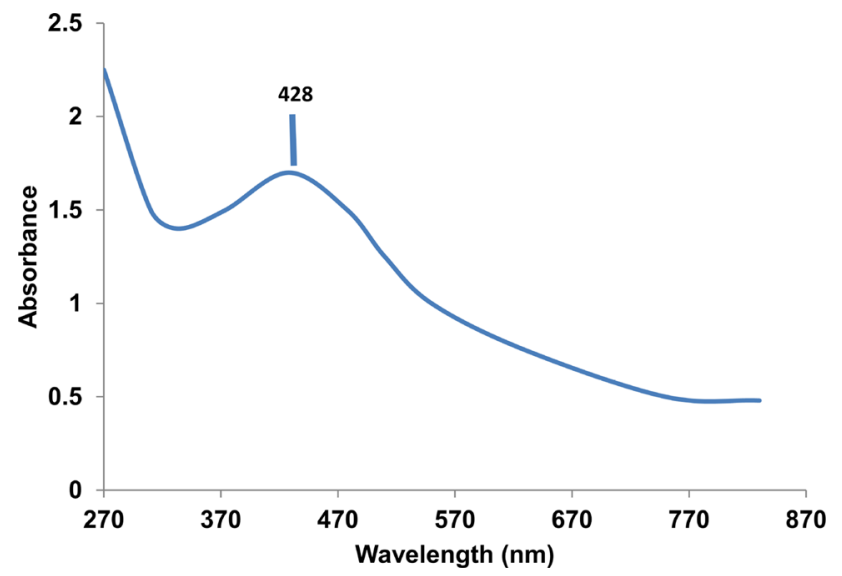

Fig. 2 UV-Vis spectrum of the biosynthesized AgNPs

Vis spectrum. Such AgNPs structures as hexagon, rhombus, 3-D triangle, rod and sphere were formed by the nest extract, which may be indicative of the richness and diversity of biomolecules present in the nest. Although green synthesis of spherical AgNPs abound in the literature, some authors have reported the formation of other shapes, such as triangle, pyramid, pentagon, hexagon, and other irregular ones (Vigneshwaran et al. 2006; Saifuddin et al. 2009; Rajakumar and Rahuman 2011; Santhoshkumar et al. 2011; Silambarasan and Jayanthi 2013). The selected electron area diffraction (SAED) showed that the AgNPs had crystalline nature (Fig. 4b) typical of $\mathrm{Ag}$ as shown by the ring-like pattern (Shankar et al. 2014), while the energy dispersive X-ray study showed the prominent presence of Ag (Fig. 4c).

\section{Antimicrobial activities of AgNPs}

The biosynthesized AgNPs showed potent antibacterial and antifungal activities on some selected strains. At concentrations of 60,80 , and $100 \mu \mathrm{g} / \mathrm{ml}$, the AgNPs depicted antibacterial activities in the range of $12-35 \mathrm{~mm}$ against multi-drug resistant isolates of Klebsiella granulomatis and Pseudomonas aeruginosa (Fig. 5). The activities shown by the AgNPs are consistent with several reports on the antibacterial activities of AgNPs (Shankar et al. 2014; Emeka et al. 2014; Kathiraven et al. 2015; Anandalakshmi et al. 2015; Lateef et al. 2015a, b, c, d; Waghmare et al. 2015). The antibacterial activities of AgNPs have been linked to the interaction of AgNPs with sulfur and phosphorus containing constituents of the bacterial cell to initiate cell killing by attacking the respiratory chain and cell division (Mahendra et al. 2009). The antibacterial activity of the AgNPs against multi-drug resistant strains is noteworthy, in view of widespread occurrence of multi-drug resistant bacteria in diverse samples from the environment (Lateef 2004; Lateef et al. 2007, 2010; Lateef and Ojo 2016). Therefore, the potency of the AgNPs can enhance its application in combating drug-resistant bacteria. 
Fig. 3 FTIR spectrum of the biosynthesized AgNPs

Fig. 4 Transmission electron micrograph (a), SAED pattern (b), and EDX spectrum (c) of the biosynthesized AgNPs
60

Smoothing
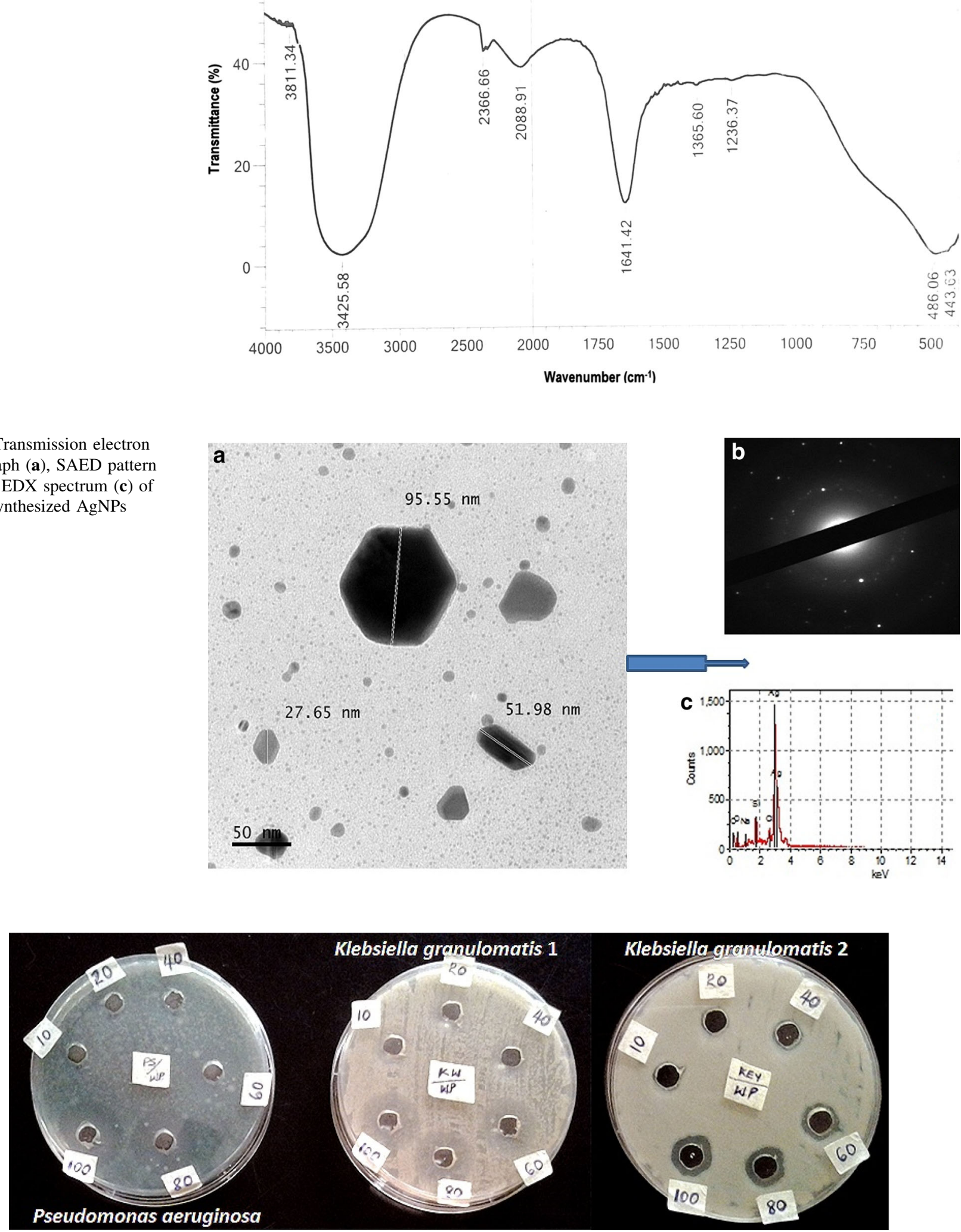

Fig. 5 Antibacterial activities of biosynthesized AgNPs 
The AgNPs completely inhibited the growth of Aspergillus niger and Aspergillus flavus at tested concentrations of 100 and $150 \mu \mathrm{g} / \mathrm{ml}$, whereas fungal growth inhibition of $75.61 \%$ was achieved with Aspergillus fumigatus (Fig. 6). These observations are in contrast to the profuse growth that were obtained on the control plates. The antifungal activities agree with previously published results (Khatami et al. 2015; Ojo et al. 2016; Netala et al. 2015). The results obtained in this study have shown that the biosynthesized AgNPs can be used as potent antifungal agents.

\section{Degradation of malachite green using AgNPs}

At concentrations of 20 and $40 \mu \mathrm{g} / \mathrm{ml}$, the biosynthesized AgNPs showed degradation of malachite green in the range of $64.3-93.1 \%$ during the period of 1-24 h (Fig. 7). The use of nanoparticles for the catalytic degradation of dyes has gained tremendous attention, as it is more advantageous than conventional methods, such as absorption, adsorption, coagulation, flocculation, ultrafiltration, reverse osmosis, and membrane technologies, that merely concentrate or transfer organic compounds from one phase to another (Soltani et al. 2012). The catalytic degradation of dyes by nanoparticles is achieved by serving as electron

Fig. 6 Antifungal activities of biosynthesized AgNPs transfer mediators between active biomolecules borne on particles and dyes in a process termed electron relay effect (Gupta et al. 2011). The results obtained in this study have further showed that biosynthesized AgNPs could be deployed for the catalytic degradation of dyes in industrial wastewaters.

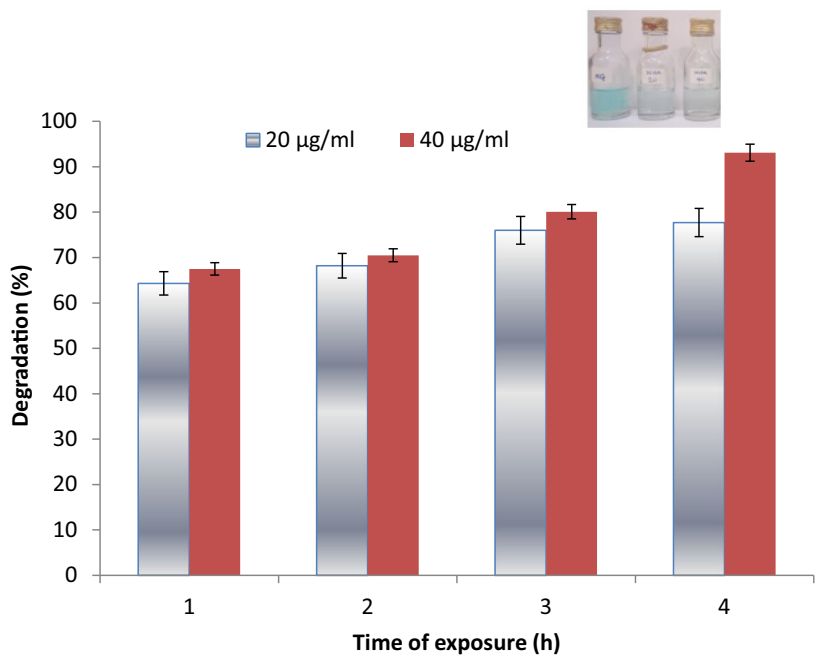

Fig. 7 Degradation of malachite green by biosynthesized AgNPs
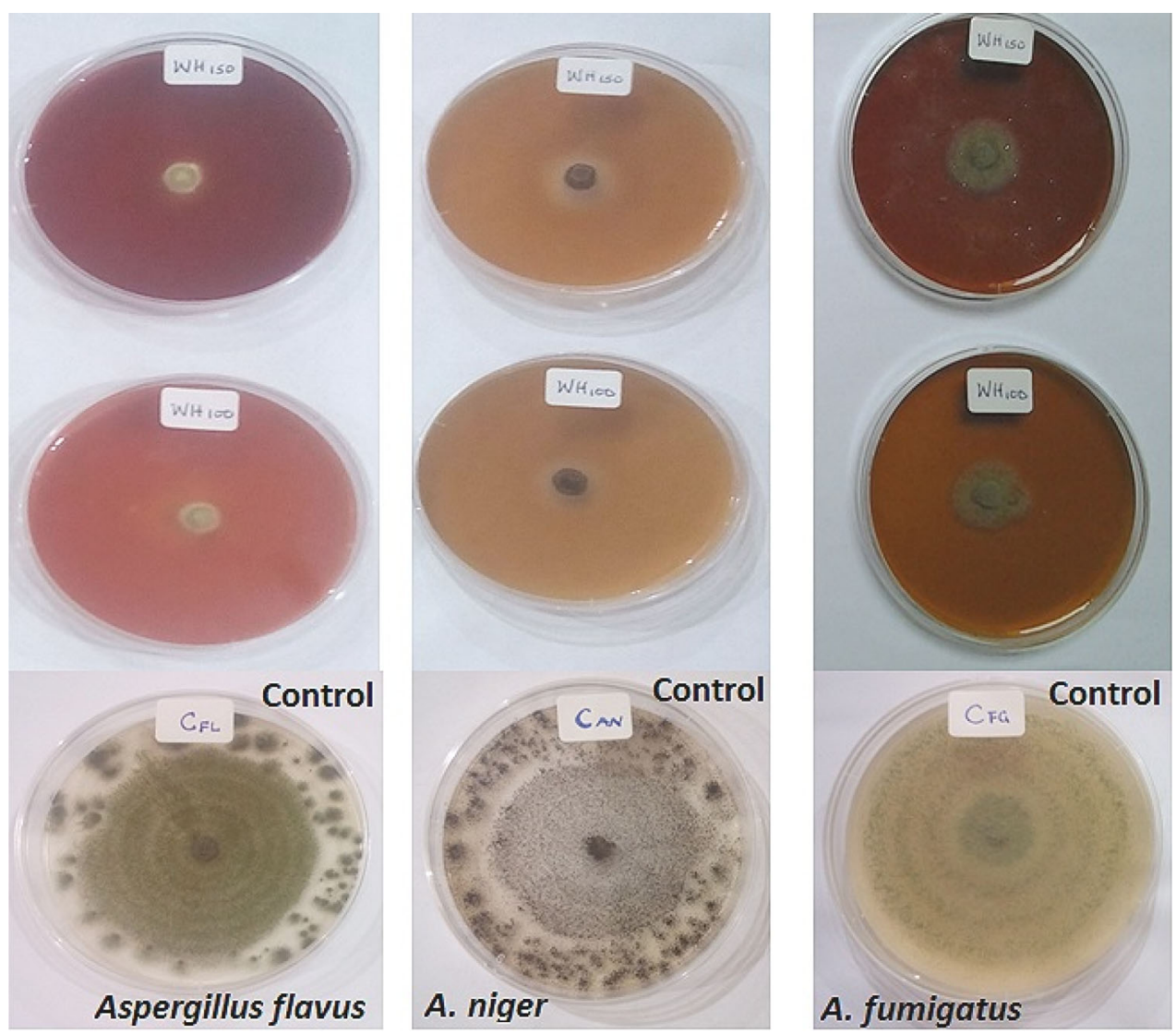


\section{Anticoagulant and thrombolytic activities of AgNPs}

The AgNPs showed potent blood anticoagulation and thrombolytic activities from the slide and microscopic observations (Fig. 8a-c). The AgNPs prevented formation of blood clot when used as anticoagulation agent (Fig. 8a3), which compared favorably with the positive control using EDTA (Fig. 8a2). Microscopic examination depicted dispersed red blood cells in EDTA-treated blood (Fig. 8a1) and AgNPs-treated blood (Fig. 8a4). The blood coagulation system is important to maintain steady blood flow, forestall bleeding and assists the innate immune system to prevent the spread of infectious agents (Esmon et al. 2011). This is not without a disadvantage, as the formation of blood clot arising from infection can damage tissues and leads to organ failure (Levi et al. 2010), often associated with cardiovascular disorders, autoimmune reactions, allergic responses, injuries, and emergence of cancer (Prandoni et al. 2007; Davalos and Akassoglou 2012). In addition, cancer cells can trigger blood coagulation through several processes, such as induction of proinflammatory cytokines, expression of procoagulant molecules on their surfaces and interaction with blood platelets (Jurasz et al. 2004; ten Cate and Falanga 2007).

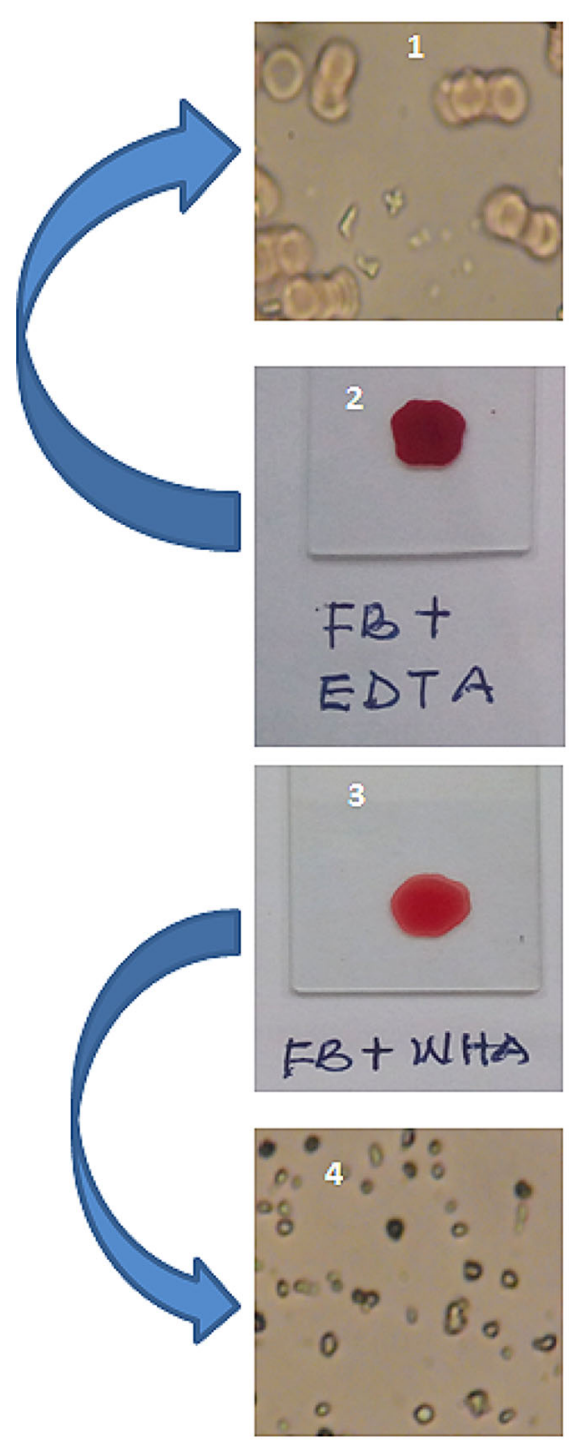

a

\section{Microscopic view}
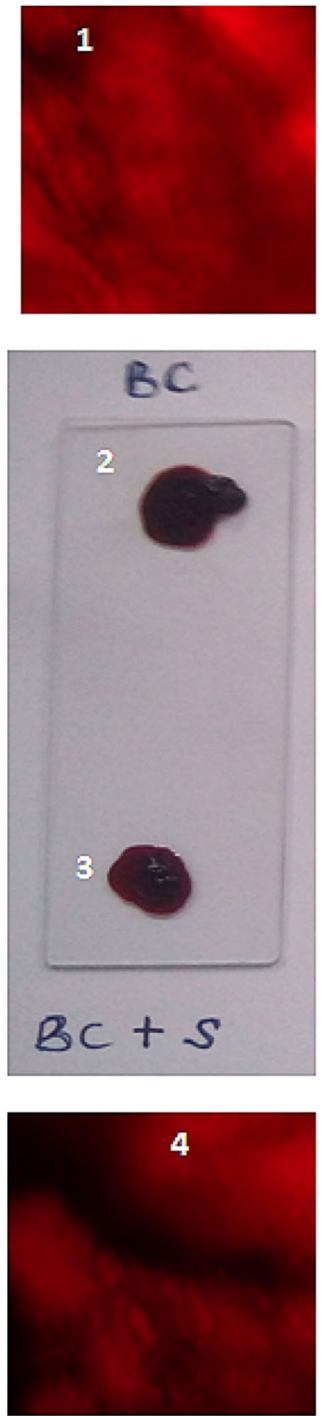

Microscopic view

b
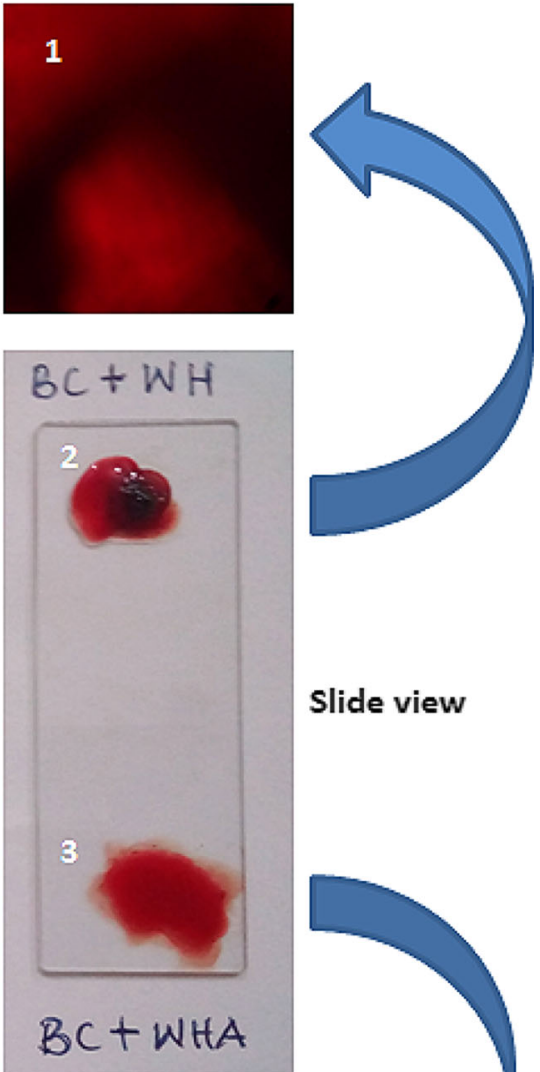

Slide view
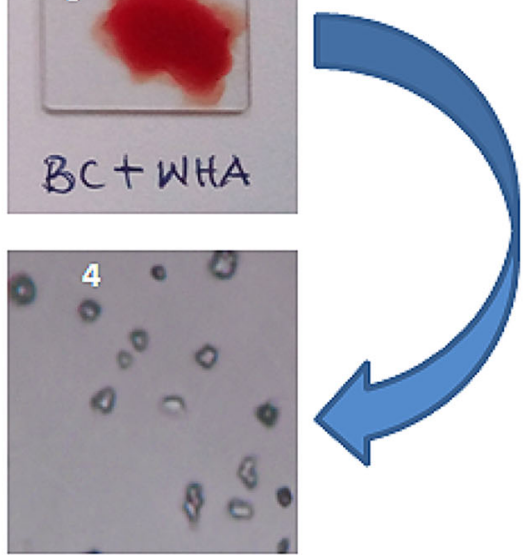

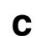

Fig. 8 Anticoagulant (a), and thrombolytic activities $(\mathbf{b}, \mathbf{c})$ of biosynthesized AgNPs ( $F B$ fresh blood, EDTA anticoagulant, WHA wasp nest extract AgNPs, $B C$ blood clot, $S \mathrm{AgNO}_{3}$ solution, $W H$ wasp nest extract only) 
In view of the complications that may arise from the blood coagulation disorders, it has become necessary to control the blood coagulation system to maintain a healthy state. This involves the prevention of aggregation of platelets, which can be achieved by AgNPs as previously demonstrated (Shrivastava et al. 2009) to inhibit the formation of thrombus. The non-toxicity of AgNPs to platelets and its profound antimicrobial activities can open a new regime of treatment of thrombosis. It has been shown that nanoparticles can impact varying degrees of influence on the blood coagulation system as a result of their size, charge, shape, and composition (Ilinskaya and Dobrovolskaia 2013). In addition to the sole use of AgNPs and perfluorocarbon emulsion (Lowe 2000) as antiplatelet agents, nanoparticles, such as gold (Hsu et al. 2011; Shiang et al. 2011) and iron oxides, can be used as carriers of active drugs to reduce the limitations of short half-life, prohibitive cost, and incidence of bleeding and hemorrhagic stroke in the prevention of coagulation of blood. The reformulation of traditional drugs such as heparin onto nanotechnology carrier platforms has potential to achieve reduced dosage, increased drug stability, increased shelflife, and overall reduction in the cost of treatment (Ilinskaya and Dobrovolskaia 2013). It can, therefore, be inferred that the potency shown by AgNPs obtained in this study can have useful applications in nanomedicine for the prevention of blood coagulation.

The AgNPs dissolved the preformed blood clot on slides almost instantaneously with very high thrombolytic activity (Fig. 8c3), whereas the negative controls of $\mathrm{AgNO}_{3}-$ treated (Fig. 8b3) and nest extract-treated (Fig. 8c2) blood clots did not lead to lysis of the blood clot. The result obtained in this study is similar to thrombolytic activity of xylan-mediated AgNPs as reported by Harish et al. (2015). Furthermore, microscopic views of the samples showed clear dispersion of the blood clot by AgNPs (Fig. 8c4), unlike the negative controls (Fig. 8b1, b4, c1). While blood clotting is necessary to curb excessive bleeding, its timely dissolution is equally important to prevent thrombosis and maintain homeostasis (Ilinskaya and Dobrovolskaia 2013). The timely and efficient dissolution of blood clot are key factors in achieving desirable outcome in patients with ischemia (inadequate supply of blood to organs) (Ilinskaya and Dobrovolskaia 2013), thereby necessitating optimization of the treatment regimes using nanotechnology. The traditional antithrombotic treatments, such as streptokinase, have such limitations in their suitability for application, including short half-life, neutralization of the foreign agents by antibodies, and danger of excessive bleeding. Interventions such as use of liposomes that can resist rapid degradation have been used as carriers of streptokinase with improved thrombolytic activity (Vaidya et al. 2011). Though there is limited information on the use of AgNPs as thrombolytic agent, the report herein presented is a further proof to the potential application of biogenic AgNPs as thrombolytic agent in the management thrombosis. We have also recently showed that $\mathrm{Au}$ and Ag-AuNPs possessed anticoagulant and thrombolytic activities (Ojo et al. 2016; Lateef et al. 2016c), with potential for biomedical applications.

\section{Conclusion}

This study has, for the first time, demonstrated the ecofriendly synthesis of AgNPs using the nest extract of paper wasp. The biosynthesized AgNPs which absorbed maximally at $428 \mathrm{~nm}$ were polydispersed in nature with the size range of 12.5-95.55 $\mathrm{nm}$, and showed anisotropic structures of sphere, triangle, hexagon, rhombus, and rod without any form aggregation. The crystalline AgNPs displayed remarkable antimicrobial activities against multi-drug resistant bacteria and fungi, and also degraded malachite green under ambient conditions to the tune of $93.1 \%$. In addition, potent blood anticoagulation and thrombolytic activities were obtained for the AgNPs. These activities have shown that the nest-mediated AgNPs can find useful biomedical and catalytic applications, particularly as antimicrobial, dye degradation, anticoagulant and thrombolytic agents. To the best of our knowledge, this is the first report of the biogenic synthesis of AgNPs using the metabolite of paper wasp, which adds to the growing utilization of novel biomaterials of arthropods in nanobiotechnology.

Acknowledgments AL grateful acknowledged the authority of LAUTECH, Ogbomoso for the provision of some of the facilities used in this study.

\section{Compliance with ethical standrads}

Conflict of interest The authors declare that there is no conflict of interest.

Open Access This article is distributed under the terms of the Creative Commons Attribution 4.0 International License (http:// creativecommons.org/licenses/by/4.0/), which permits unrestricted use, distribution, and reproduction in any medium, provided you give appropriate credit to the original author(s) and the source, provide a link to the Creative Commons license, and indicate if changes were made.

\section{References}

Anandalakshmi K, Venugobal J, Ramasamy V (2015) Characterization of silver nanoparticles by green synthesis method using Pedalium murex leaf extract and their antibacterial activity. Appl Nanosci. doi:10.1007/s13204-015-0449-z 
Aramwit P, Bang N, Ratanavaraporn J, Ekgasit S (2014) Green synthesis of silk sericin-capped silver nanoparticles and their potent anti-bacterial activity. Nanoscale Res Lett 9:1-7

Clapperton BK, Lo PL (2000) Nesting biology of Asian paper wasps Polistes chinensis antennalis Perez, and Australian paper wasps Polistes humilis (Fabricius) (Hymenoptera, Vespidae) in northern New Zealand. N Z J Zool 27:189-195

Das VL, Thomas R, Varghese RT, Soniya EV, Mathew J, Radhakrishnan EK (2014) Extracellular synthesis of silver nanoparticles by the Bacillus strain CS 11 isolated from industrialized area. 3 . Biotech 4:121-126

Davalos D, Akassoglou K (2012) Fibrinogen as a key regulator of inflammation in disease. Sem Immunopathol 34:43-62

Emeka EE, Ojiefoh OC, Aleruchi C, Hassan LA, Christiana OM, Rebecca M, Dare EO, Temitope AE (2014) Evaluation of antibacterial activities of silver nanoparticles green-synthesized using pineapple leaf (Ananas comosus). Micron 57:1-5

Esmon CT, Xu J, Lupu F (2011) Innate immunity and coagulation. J Thromb Haemost 9:182-188

Evans HE, West-Eberhard MJ (1970) The Wasps. University of Michigan Press, Ann Arbor

Gupta N, Singh HP, Sharma RK (2011) Metal nanoparticles with high catalytic activity in degradation of methyl orange: an electron relay effect. J Mol Catal A Chem 335:248-252

Harish BS, Uppuluri KB, Anbazhagan V (2015) Synthesis of fibrinolytic active nanoparticles using wheat bran xylan as a reducing and stabilizing agent. Carbohydr Polymer 132:104-110

Hsu CL, Chang HT, Chen CT, Wei SC, Shiang YC, Huang CC (2011) Highly efficient control of thrombin activity by multivalent nanoparticles. Chem 17:10994-11000

Ilinskaya AN, Dobrovolskaia MA (2013) Nanoparticles and the blood coagulation system. Part I: benefits of nanotechnology. Nanomed 8:773-784

Jurasz P, Alonso-Escolano D, Radomski MW (2004) Platelet-cancer interactions: mechanisms and pharmacology of tumour cellinduced platelet aggregation. Brit J Pharmacol 143:819-826

Kathiraven T, Sundaramanickam A, Shanmugam N, Balasubramanian $\mathrm{T}$ (2015) Green synthesis of silver nanoparticles using marine algae Caulerpa racemosa and their antibacterial activity against some human pathogens. Appl Nanosci 5:499-504

Keat CL, Aziz A, Eid AM, Elmarzugi NA (2015) Biosynthesis of nanoparticles and silver nanoparticles. Bioresour Bioprocessing 2:47

Khatami M, Pourseyedi S, Khatami M, Hamidi H, Zaeifi M, Soltani L (2015) Synthesis of silver nanoparticles using seed exudates of Sinapis arvensis as a novel bioresourse, and evaluation of their antifungal activity. Bioresour Bioprocess 2:19

Kudô K, Hozumi S, Yamamoto H, Yamane S (2000a) Amino acid composition of the protein in preemergence nests of Polistes (Polistes) riparius, and its similarity to the consubgeneric wasp, P. (P.) chinensis (Hymenoptera: Vespidae). J Ethol 18:75-77

Kudô K, Yamamoto H, Yamane S (2000b) Amino acid composition of the protein in pre-emergence nests of a paper wasp, Polistes chinensis (Hymenoptera, Vespidae). Insectes Soc 47:371-375

Kumar R, Roopan SM, Prabhakarn A, Khanna VG, Chakroborty S (2012) Agricultural waste Annona squamosa peel extract: biosynthesis of silver nanoparticles. Spectrochim Acta Part A Mol Biomol Spectr 90:173-176

Kumar DA, Palanichamy V, Roopan SM (2014) Green synthesis of silver nanoparticles using Alternanthera dentata leaf extract at room temperature and their antimicrobial activity. Spectrochim Acta Part A Mol Biomol Spectr 127:168-171

Lateef A (2004) The microbiology of a pharmaceutical effluent and its public health implications. World J Microbiol Biotechnol 20:167-171
Lateef A, Adeeyo AO (2015) Green synthesis and antibacterial activities of silver nanoparticles using extracellular laccase of Lentinus edodes. Not Sci Biol 7:405-411

Lateef A, Ojo MO (2016) Public health issues in the processing of cassava (Manihot esculenta) for the production of 'lafun' and the application of hazard analysis control measures. Qual Assur Safety Crops Fds 8:165-177

Lateef A, Yekeen TA, Ufuoma PE (2007) Bacteriology and genotoxicity of some pharmaceutical wastewaters in Nigeria. Int J Environ Health 1(4):551-562

Lateef A, Davies TE, Adelekan A, Adelere IA, Adedeji AA, Fadahunsi AH (2010) Akara Ogbomoso: microbiological examination and identification of hazards and critical control points. Fd Sci Technol Int 16:389-400

Lateef A, Adelere IA, Gueguim-Kana EB, Asafa TB, Beukes LS (2015a) Green synthesis of silver nanoparticles using keratinase obtained from a strain of Bacillus safensis LAU 13. Int Nano Lett 5:29-35

Lateef A, Azeez MA, Asafa TB, Yekeen TA, Akinboro A, Oladipo IC, Ajetomobi FE, Gueguim-Kana EB, Beukes LS (2015b) Cola nitida-mediated biogenic synthesis of silver nanoparticles using seed and seed shell extracts and evaluation of antibacterial activities. BioNanoSci 5:196-205

Lateef A, Ojo SA, Akinwale AS, Azeez L, Gueguim-Kana EB, Beukes LS (2015c) Biogenic synthesis of silver nanoparticles using cell-free extract of Bacillus safensis LAU 13: antimicrobial, free radical scavenging and larvicidal activities. Biologia 70:1295-1306

Lateef A, Ojo SA, Azeez MA, Asafa TB, Yekeen TA, Akinboro A, Oladipo IC, Gueguim-Kana EB, Beukes LS (2015d) Cobweb as novel biomaterial for the green and eco-friendly synthesis of silver nanoparticles. Appl Nanosci. doi:10.1007/s13204-0150492-9

Lateef A, Azeez MA, Asafa TB, Yekeen TA, Akinboro A, Oladipo IC, Azeez L, Ajibade SE, Ojo SA, Gueguim-Kana EB, Beukes LS (2016a) Biogenic synthesis of silver nanoparticles using pod extract of Cola nitida: antibacterial, antioxidant activities and application as additive paint. J Taibah Univ Sci. doi:10.1016/j. jtusci.2015.10.010

Lateef A, Azeez MA, Asafa TB, Yekeen TA, Akinboro A, Oladipo IC, Azeez L, Ojo SA, Gueguim-Kana EB, Beukes LS (2016b) Cocoa pod extract-mediated biosynthesis of silver nanoparticles: its antimicrobial, antioxidant and larvicidal activities. J Nanostruct Chem 6:159-169

Lateef A, Ojo SA, Folarin BI, Gueguim-Kana EB, Beukes LS (2016c) Kolanut (Cola nitida) mediated synthesis of silver-gold alloy nanoparticles: antifungal, catalytic, larvicidal and thrombolytic applications. J Clust Sci. doi:10.1007/s10876-016-1019-6

Levi M, Schultz M, van der Poll T (2010) Disseminated intravascular coagulation in infectious disease. Sem Thromb Hemost 36:367-377

Lowe KC (2000) Second-generation perfluorocarbon emulsion blood substitutes. Artif Cells Blood Substit Biotechnol 82:25-38

Mahendra R, Alka Y, Aniket G (2009) Silver nanoparticles as a new generation of antimicrobials. Biotechnol Adv 27:76-83

Metuku RP, Pabba S, Burra S, Gudikandula K, Charya MS (2014) Biosynthesis of silver nanoparticles from Schizophyllum radiatum HE 863742.1: their characterization and antimicrobial activity. 3 Biotech 4:227-234

Netala VR, Kotakadi VS, Domdi L, Gaddam SA, Bobbu P, Venkata SK, Ghosh SB, Tartte V (2015) Biogenic silver nanoparticles: efficient and effective antifungal agents. Appl Nanosci. doi:10. 1007/s13204-015-0463-1

Nguyen LTP, Kojima JI (2014) Distribution and nests of paper wasps of Polistes (Polistella) in northeastern Vietnam, with description of a new species (Hymenoptera, Vespidae, Polistinae). ZooKeys 368:45

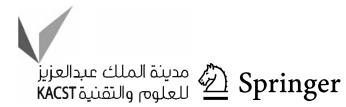


Ojo SA, Lateef A, Azeez MA, Oladejo SM, Akinwale AS, Asafa TB, Yekeen TA, Akinboro A, Oladipo IC, Gueguim-Kana EB, Beukes LS (2016) Biomedical and catalytic applications of gold and silver-gold alloy nanoparticles biosynthesized using cell-free extract of Bacillus safensis LAU 13: antifungal, dye degradation, anti-coagulant and thrombolytic activities. IEEE Trans Nanobiosci. doi:10.1109/TNB.2016.2559161

Prandoni P, Falanga A, Piccioli A (2007) Cancer, thrombosis and heparin-induced thrombocytopenia. Thromb Res 120:S137S140

Rajakumar G, Rahuman AA (2011) Larvicidal activity of synthesized silver nanoparticles using Eclipta prostrata leaf extract against filariasis and malaria vectors. Acta Trop 118:196-203

Roopan SM, Madhumitha G, Rahuman AA, Kamaraj C, Bharathi A, Surendra TV (2013) Low-cost and eco-friendly phyto-synthesis of silver nanoparticles using Cocos nucifera coir extract and its larvicidal activity. Ind Crops Prod 43:631-635

Saifuddin N, Wong W, Yasumira AA (2009) Rapid biosynthesis of silver nanoparticles using culture supernatant of bacteria with microwave irradiation. E J Chem 6:61-70

Santhoshkumar T, Rahuman AA, Rajakumar G, Marimuthu S, Bagavan A, Jayaseelan C, Zahir AA, Elango G, Kamaraj C (2011) Synthesis of silver nanoparticles using Nelumbo nucifera leaf extract and its larvicidal activity against malaria and filariasis vectors. Parasitol Res 108:693-702

Shankar S, Jaiswal L, Aparna RSL, Prasad RGSV (2014) Synthesis, characterization, in vitro biocompatibility, and antimicrobial activity of gold, silver and gold silver alloy nanoparticles prepared from Lansium domesticum fruit peel extract. Mater Lett 137:75-78

Shiang YC, Hsu CL, Huang CC, Chang HT (2011) Gold nanoparticles presenting hybridized self-assembled aptamers that exhibit enhanced inhibition of thrombin. Angew Chem 123:7802-7807

Shrivastava S, Bera T, Singh SK, Singh G, Ramachandrarao P, Dash D (2009) Characterization of antiplatelet properties of silver nanoparticles. ACS Nano 3:1357-1364

Silambarasan S, Jayanthi A (2013) Biosynthesis of silver nanoparticles using Pseudomonas fluorescens. Res J Biotechnol 8:71-75

Singer TL, Espelie KE, Himmelsbach DS (1992) Ultrastructural and chemical examination of paper and pedicel from laboratory and field nests of the social wasp Polistes metricus Say. J Chem Ecol 18:77-86

Sinzato DM, Andrade FR, De Souza AR, Del-Claro K, Prezoto F (2011) Colony cycle, foundation strategy and nesting biology of a neotropical paper wasp. Rev Chil de Hist Nat 84:357-363
Soltani N, Saion E, Hussein MZ, Erfani M, Abedini A, Bahmanrokh G, Navasery M, Vaziri P (2012) Visible light-induced degradation of methylene blue in the presence of photocatalytic $\mathrm{ZnS}$ and CdS nanoparticles. Int J Mol Sci 13:12242-12258

ten Cate H, Falanga A (2007) Overview of the postulated mechanisms linking cancer and thrombosis. Pathophysiol Haemost Thromb $36: 122-130$

Tszydel M, Sztajnowski S, Michalak M, Wrzosek H, Kowalska S, Krucińska I, Lipp-Symonowicz B (2009) Structure and physical and chemical properties of fibres from the fifth larval instar of caddis-flies of the species Hydropsyche angustipennis. Fibres Text East Eur 17:7-12

Vaidya B, Agrawal GP, Vyas SP (2011) Platelets directed liposomes for the delivery of streptokinase: development and characterization. Eur J Pharmaceut Sci 44:589-594

Velayutham K, Rahuman AA, Rajakumar G, Roopan SM, Elango G, Kamaraj C, Marimuthu S, Santhoshkumar T, Iyappan M, Siva C (2013) Larvicidal activity of green synthesized silver nanoparticles using bark aqueous extract of Ficus racemosa against Culex quinquefasciatus and Culex gelidus. Asian Pac J Trop Med 6:95-101

Vigneshwaran N, Kathe AA, Varadarajan PV, Nachane RP, Balasubramanya RH (2006) Biomimetics of silver nanoparticles by white rot fungus, Phaenerochaete chrysosporium. Coll Surf B Biointerf 53:55-59

Waghmare SR, Mulla MN, Marathe SR, Sonawane KD (2015) Ecofriendly production of silver nanoparticles using Candida utilis and its mechanistic action against pathogenic microorganisms. 3 Biotech 5:33-38

Wenzel JW (1996) Learning, behaviour programs, and higher-level rules in the nest construction of Polistes. In: Turillazzi S, WestEberhard MJ (eds) Natural history and evolution of paper-wasp. Oxford University Press, Oxford, pp 58-74

West-Eberhard MJ (2006) Polistes passions. Ann Zool Fenn 43:387-389

Xu S, Yong L, Wu P (2013) One-pot, green, rapid synthesis of flowerlike gold nanoparticles/reduced graphene oxide composite with regenerated silk fibroin as efficient oxygen reduction electrocatalysts. ACS Appl Mater Interf 5:654-662

Yugandhar P, Haribabu R, Savithramma N (2015) Synthesis, characterization and antimicrobial properties of green-synthesized silver nanoparticles from stem bark extract of Syzygium alternifolium (Wt.) Walp. 3 Biotech 5:1031-1039 